Дзюба В. С. ${ }^{1}$, Потапов А. М. ${ }^{2}$, Гусарова И. А. ${ }^{2}$, Харченко В. В. ${ }^{1}$, Кравчук Л. В. ${ }^{1}$, Дроздов А. В. ${ }^{1}$

${ }^{1}$ Институт проблем прочности им. Г. С. Писаренко НАН Украины. Украина, г. Киев

${ }^{2}$ Государственное предприятие «Конструкторское бюро «Южное» им. М. К. Янгеля».

Украина, г. Днепр

\title{
ПРОЧНОСТЬ УГЛЕРОД-УГЛЕРОДНЫХ КОМПОЗИЦИОННЫХ МАТЕРИАЛОВ (УУКМ) ПРИ ВЫСОКИХ ТЕМПЕРАТУРАХ (ДО 3300 К)
}

В настоящее время иироко используются в технике композиционные материалы (в авиации, ракетостроении и др.) из-за высокой прочности, малого удельного веса, применения их в конструкциях при высоких температурах, где металл не работает. Особое место занимают углерод-углеродные композиционые материалы (УУКМ) прочность которых при высоких температурах увеличивается по сравнению с прочностью при комнатной. Целью данной публикации является исследование прочности УУКМ при температурах $300 . .3300$ К при растяжении и сжатии. В настоящее время в литературе имеются данные об этих свойствах только до 2200 К, а УУКМ используются в ракетных двигателях при T= 3300 К. Для проведения әтих исследований разработаны новая методика, созданы әкспериментальные средства и получены результаты по прочности УУКМ при растяжении, сжатии в дтпазоне температур 300...3300 К. [dx.doi.org/10.29010/084.5]

Ключевые слова: прочность; композиционный материал; температура.

Введение

Большое количество современных конструкционных элементов энергетической техники работает в условиях предельных силовых и тепловых нагрузок (в условиях температур 20...3300 К). Для работы в таких сложных условиях эксплуатации применяются новые, специально создаваемые композиционные материалы (КМ). В качестве материалов для конструкций, которые работают в условиях высоких температур, из-за своих уникальных свойств (высокая прочность, низкая теплопроводность, высокие энтальпийные свойства) широко используют углерод-углеродные композитные материалы (УУКМ) в условиях температур до 3300 К. Для эффективного использования КМ очень важно получение достоверных сведений об их механических свойствах в условиях, максимально близких к эксплуатационным. Специфика этого класса материалов и условий его работы обусловливает необходимость разработки и использования ряда неординарных подходов и методических решений. До настоящего времени в литературе имеются сведения о механических свойствах этих материалов (прочности, деформируемости, упругости) при температурах до 2300 К. В этой публикации приведены новые данные о механических свойствах УУКМ при температурах 300-3300 К и скоростях нагрева до 1000 К/сек, которые получены авторами, используя специально созданный испытательный комплекс.

\section{Постановка задачи}

Целью настоящего сообщения является краткое описание особенностей методической и экспериментальной базы, а также представление некоторых результатов исследования кратковременной прочности композиционных материалов (УУКМ) при растяжении, сжатии в диапазоне температур 293 ... 3300 К.

Методики и экспериментальный комплекс для проведения высокотемпературных испытаний

УУКМ при различных видах нагружения

Для реализации поставленной задачи в Институте проблем прочности им. Г. С. Писаренко НАН Украины на базе систем универсальной машины 1958У-10-1 создан и эксплуатируется испытательный комплекс для исследования термомеханических свойств углерод-углеродных композиционных материалов при растяжении, сжатии кручении в условиях температур до 3300 К в вакууме, окислительной или инертной среде (рис. 1).

Основные технические характеристики комплекса.

Вид нагружения образиа растяжение, сжатие, изгиб, сдвиг, кручение (кратковременное статическое, длительное, циклическое)

Кравчук Л. В., Дроздов А. В., 2018 


\section{технологиически: TC 3/2018}

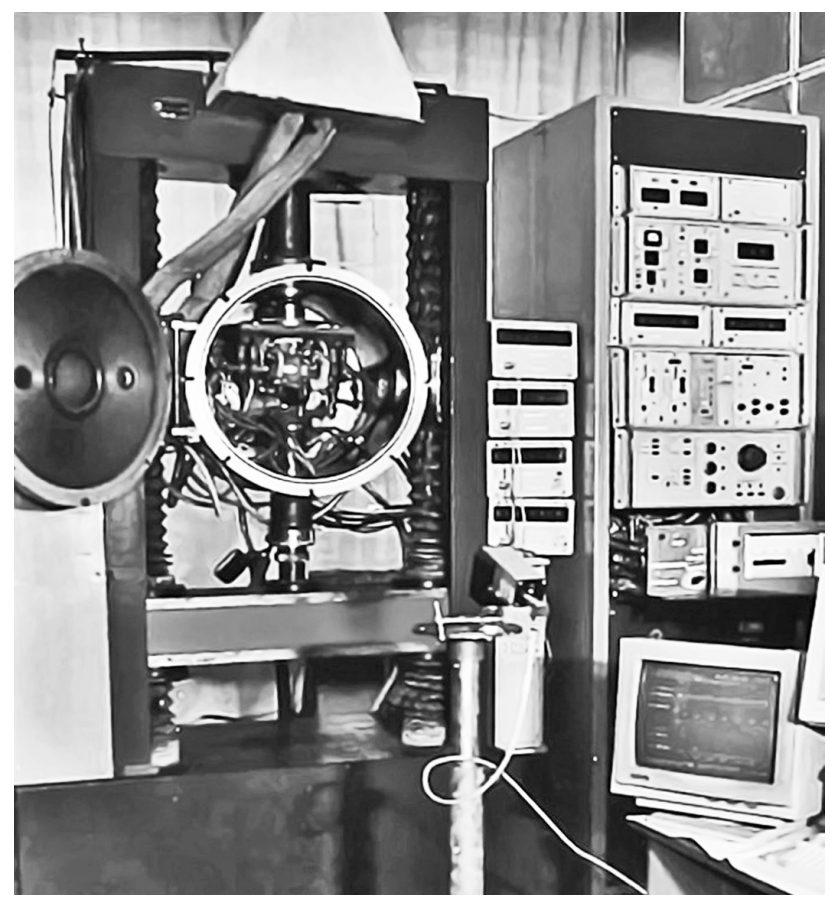

Рис. 1. Комплекс для испытаний УУКМ при различных видах нагружения в условиях температур до 3300 K
Диапазон нагрузок, кН
$0.002 \ldots 100$
Диапазон рабочих
температур, $\mathrm{K}$
$290 \ldots 3300$
Скорость
нагрева, град/сек
Диапазон скорости
деформирования, мм/мин
до 1000
$0.005 \ldots 500$

Создание экспериментального комплекса позволяет проводить испытания полностью в автоматическом режиме с возможностью задания практически любых программ по нагружению и нагреву со скоростью до 1000 град/сек при поддержании равномерного поля температур по длине рабочей зоны образца. Разработка оригинальных образцов и методик для разных видов испытаний позволила измерять деформацию рабочей зоны с высокой точностью во всем диапазоне температур. Благодаря возможности программного изменения характера нагружения и реализация различных режимов мягкого, жесткого или смешанного деформирования в процессе испытания образца система механического нагружения позволяет решать специфические вопросы высокотемпературных испытаний, в частности, компенсации температурных деформаций образца в процессе нагрева. Это обеспечивается последовательной работой на режимах поддержания постоянной минимальной нагрузки (аналог испытаний на ползучесть) до достижения заданного уровня температуры и последующего активного нагружения с заданной скоростью деформирования до разрушения.
К принципиальным особенностям конструкции комплекса следует отнести следующие.

Для испытаний в средах (вакуум, воздух, инертный газ) и обеспечения условий функционирования базовых систем (нагружения, нагрева, измерения) служит двухсекционная камера, которая вместе с переходными сильфонными уплотнениями составляет герметичную полость. В первой секции расположены все элементы передачи нагрузки на образец, передающие элементы систем измерения деформаций, термопары, коммуникационные устройства электрических цепей, систем охлаждения, вакуумирования и подачи инертного газа. Во второй секции, отделенной от первой системой экранов, расположена тензометрическая измерительная часть. Визуальное наблюдения (в т.ч. фото киносъемка) за поведением образца и дистанционное измерение температуры пирометром производится через иллюминатор.

Для реализации режимов нагрева, близких к эксплуатационным, в установке используется способ прямого пропускания электрического тока, обеспечивающий весьма высокие скорости нагрева при практически однородном температурном поле в поперечном сечении образца. Для создания равномерного поля температур по длине рабочей части образца разработана оригинальная методика дополнительного подогрева ее краев. Принципиально процесс нагрева реализуется по схеме, показанной на рис. 2 при испытаниях на растяжение $(a)$, сжатие (б) и кручение $(8)$.

Режим теплового нагружения определяется работой трех электрически не связанных источников питания, программируемых от единой системы управления нагревом. При испытаниях основное переменное напряжение $\left(V_{1}\right)$ для нагрева рабочей части подводится непосредственно к водоохлаждаемым захватам, а напряжения $V_{2}$ и $V_{3}$ - для подогрева краев рабочей части - к тоководам, расположенным на захватах и электрически изолированных от них. Такая привязка всех тоководов к захватам обеспечивает постоянное отслеживание перемещения зон электрического контакта в процессе деформирования образца и произвольного их перемещения в процессе испытаний. Оптимизация соотношения напряжений обеспечивает необходимую скорость нагрева, компенсацию оттока тепла в захваты и, тем самым, минимизацию градиента температуры по длине образца.

Управление испытаниями и запись данных эксперимента реализуется с помощью ЭВМ. Система измерения данных эксперимента (СИДЭ) включает в себя комплекс датчиков, аппаратуры визуального наблюдения, а также автоматической регистрации и первичной обработки данных, характеризующих функционирование всех систем установки, параметры термосилового нагружения и деформирования образца. 

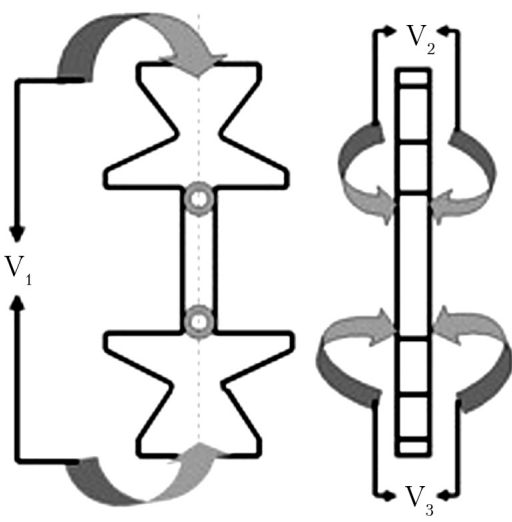

a)

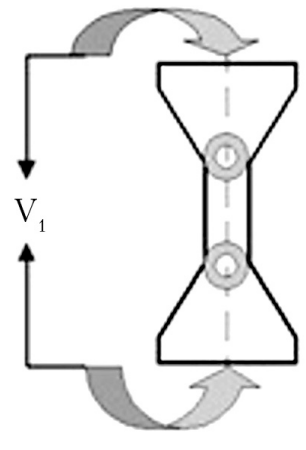

б)
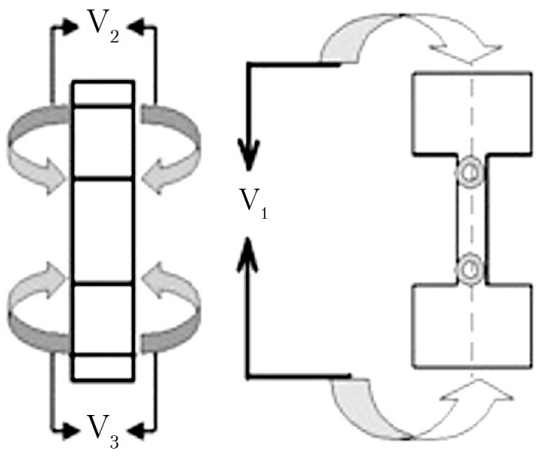

в)

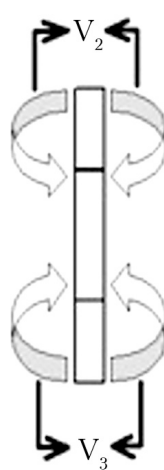

Pис. 2. Схема нагрева образцов при растяжении $(a)$, сжатии $(б)$ и кручении (в)

Модернизированная система измерения обеспечивает полное решение вопросов приема, преобразования и нормализации сигналов от различных датчиков и обеспечивающая аналого-цифровое и цифро-аналоговое преобразование сигналов, ввод-вывод дискретных (цифровых) сигналов в персональный компьютер и их последующую программную обработку с помощью оригинальной программы Test1958. При этом соблюдается защита измерительного оборудования от опасных помех, импульсных бросков напряжения, прочих отрицательно влияющих факторов.

В отличие от существующих методов измерения деформации при растяжении-сжатии в условиях высоких температур по перемещению активного захвата, в данной работе разработаны оригинальные образцы и методики, позволяющие измерять деформацию рабочей зоны (рис. 3).

Для испытаний на растяжение предложен образец сложной формы (рис. $3, a$ ) с расположенными с обеих сторон по краям рабочей части призматическими выступами. При использованном способе и

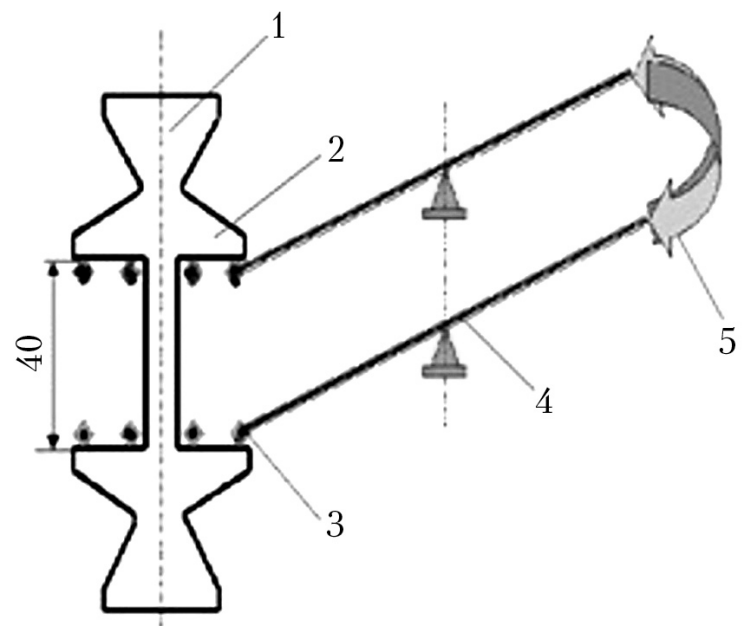

a) высоких скоростях нагрева температура на их концах составляет 1100...1200 К при температуре рабочей части 3300 К, что позволяет применять ножки из жаростойкой керамики без значительной деформации и разрушения.

Измерение деформаций осуществляется с помощью экстензометрического устройства (рис. 3), главными элементами которого являются высокотемпературные призмы (3) и помещенные в охлаждаемый отсек испытательной камеры попарно соединенные упругие скобы (5) с наклеенными тензорезисторами,

Использование схемы измерений с четырьмя независимыми каналами получения данных позволяет существенно повысить достоверность получаемых данных о деформационных свойствах материала, значительно ослабив при этом влияние возможных температурных деформаций элементов образца вне его рабочей зоны в процессе скоростного нагрева.

Для испытаний на сжатие были созданы оригинальные образцы (рис. 3, б) и модифицировано тензометрическое устройство, использованное при

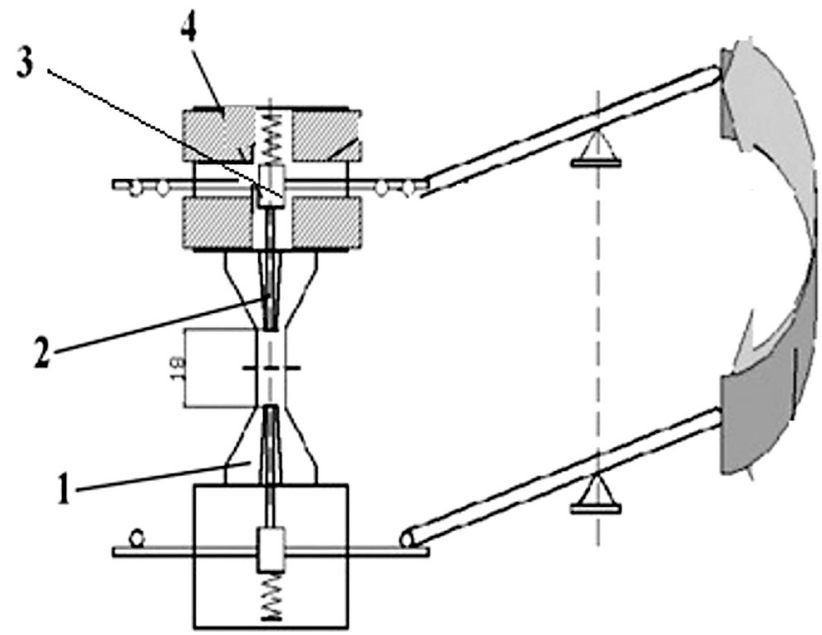

б)

Рис. 3. Схема измерения деформаций при растяжении ( $a$ ) и сжатии (б) 
растяжении. Основные изменения конструкции последнего коснулись частей, которые контактируют с образцом (1) и дополнительными промежуточными элементами. Принципиальную схему измерения деформаций рабочего участка образца иллюстрирует рис. 3 , б.

Деформацию отслеживают тонкие штоки (2), установленные в глухие конические отверстия, просверленные с торцов образца (1) по его оси до границ рабочей части. Противоположные торцы штоков упираются в дно подпружиненных плунжеров (3), соосных с захватами и свободно перемещаются в соответствующих направляющих (4). Перемещение плунжеров после температурной стабилизации системы образец-плунжер эквивалентно деформации рабочей части образца при нагружении. Следует заметить, что данная система измерения деформаций при сжатии оправдывает себя и достаточно эффективна при исследованиях начальных участков кривых деформирования, характеризуемых малыми значениями нагрузок и деформаций. При больших деформациях, сопровождающихся в некоторых случаях потерей устойчивости образца, достаточная точность измерений достигается с использованием методик, предусматривающих контроль перемещения активного захвата испытательной машины.

Для проведения испытаний при кручении [1] разработано оригинальное устройств, функциональная схема которого показана рис. 4. На схеме показаны основные принципы работы узла, способ приложение крутящего момента к образцу и замер углов закручивания рабочей части.

Определение деформаций образца при кручении проводится расчетными методами, исходными данными для которого являются углы относительного поворота захватов.

Все устройство в сборе жестко крепится к верхней неподвижной траверсе, на которой устанавливаются сменные измерители нагрузки (динамометры). В подшипниках цапф (2) установлены свободно вращающиеся валы (3), которые с одной стороны оканчиваются элементами захвата (6) образцов. Кроме центровки и защемления образца (5) на этих

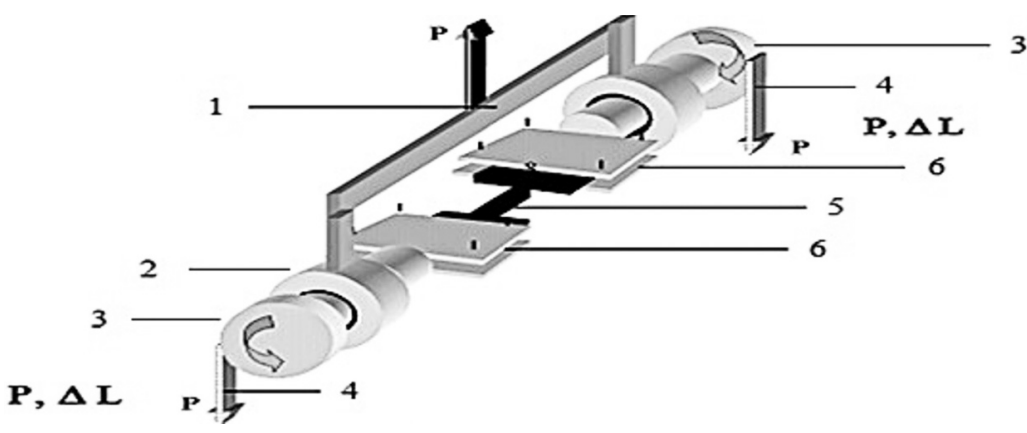

Рис. 4. Схема приложения нагрузки и измерения перемещений при кручении участках валов устанавливаются основные и дополнительные контактные устройства системы нагрева образцов, а также коммуникации системы охлаждения. На внешних концах валов устанавливаются сменные шкивы, на которых крепятся пружинные либо цепные связи (4) нагружающего устройства с подвижной траверсой (1).

Угол закручивания образца $\varphi$ измеряется путем пересчета перемещения нижней траверсы в угол поворота шкива.

Большинство композиционных материалов являются анизотропными, поэтому для нахождения сдвиговых характеристик нужны результаты нескольких испытаний. Для исследований, как правило, используют серию образцов, при изготовлении каждого из которых исследуемый материал обретает различные механические повреждения.

При каждом из видов испытаний измерение температуры рабочей части образца производилась с помощью платина-платинородиевых и вольфрамрениевых термопар и, в основном, инфракрасного (ИК) пирометра типа "INFRATHERM IGA-100" для бесконтактного измерения температур до $3300 \mathrm{~K}$.

\section{Результаты}

Создание испытательного комплекса позволило провести комплекс исследований термомеханических свойств углерод-углеродных композиционных материалов в диапазоне температур 293...3273 К со скоростью нагрева 1000 град/сек при различных видах нагружения.

Ниже приведены некоторые результаты исследований одной из композиций УУКМ при растяжении и сжатии, в наибольшей степени отражающие характер деформирования и разрушения этого класса материалов.

Для этой серии испытаний на растяжение соблюдалась программы по механическому нагружению и нагреву, представленные на рис. 5.

Обобщенные данные по зависимости кривых деформирования “ $\sigma-\varepsilon$ ”, от температуры для одной из композиции УУКМ представлены на рис. 6.

Видна общая тенденция упрочнения материала при повышении температуры до 2473 К, при которой прочность достигает своего максимума. Для более высоких температур в большей мере проявляется накопление повреждений от теплового и механического нагружений, что, в конечном счете, вызывает снижение прочности.

Анализ разрушенных образцов при растяжении показал, что практически во всем диапазоне температур наблюдалось хрупкое разрушение. 
Характерным является для этого класса материала изменение такого параметра как модуль упругости. Анализ влияния температуры (рис. 7) показал, что в отличие от характеристик прочности до температур порядка 2000 К наблюдается монотонное уменьшение модуля более чем в 2 раза по сравнению с комнатной температурой. При более высоких температурах происходит его стабилизация.

Исследования влияния температуры на физико-механические свойства УУКМ при сжимающих нагрузках показали о качественно близком ее влиянии на эти овойства, как и при растяжении. Обобщенные результаты испытания на сжатие приведены на рис. 8 .

Характеризуя температурные зависимости в целом, следует подчеркнуть следующее.

При повышении температуры до 1773 К наблюдается повышение прочности и деформационных характеристик по сравнению с комнатной температурой более чем в 2 раза. При дальнейшем повышении температуры до 2273 К снижается темп, но сохраняется увеличение прочностных и деформационных характеристик.

Дальнейшее увеличение температуры до 2473 К несущественно сказывается на прочности и деформации образцов по сравнению с 2273 К, однако наблюдается тенденция при этой температуре к снижению прочности и увеличению деформации образцов. Эти результаты косвенно показывают, что пик прочностных характеристик приходится на температуру $2273 \mathrm{~K}$. Дальнейшее повышение температуры приводит к интенсификации разупрочняющих процессов и потере работоспособности материал.

\section{Выводы}

Анализируя полученные результаты, в целом следует отметить следующее. Из приведенных экспериментальных данных видно, что влияние температуры в разных диапазонах на прочностные и деформационные свойства УУКМ при растяжении и сжатии сказывается не одинаково и принципиально отлично от поведения традиционных классов конструкционных материалов.

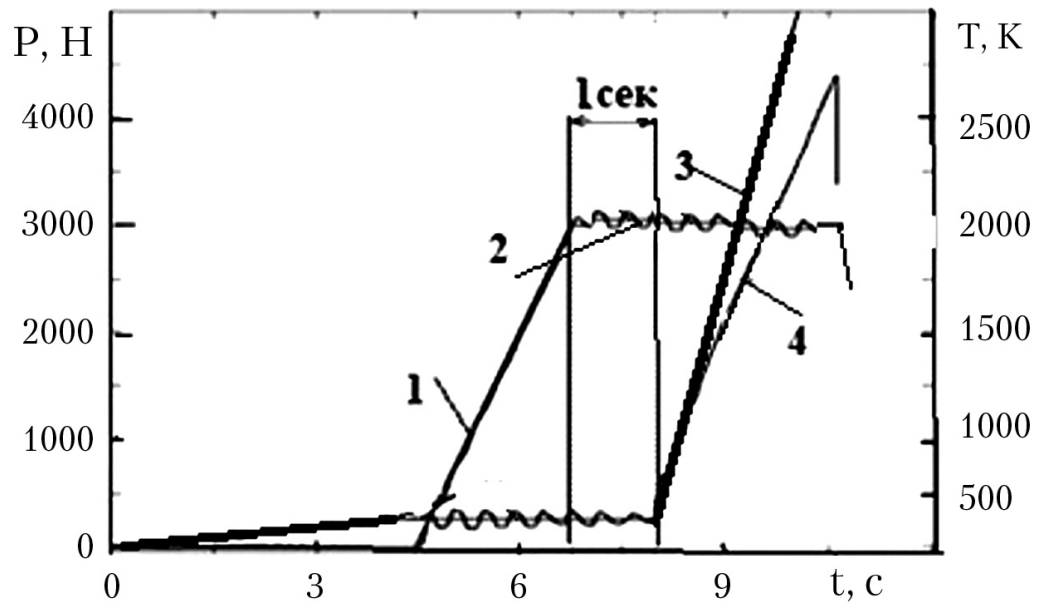

Рис. 5. Пример программ управления экспериментом при испытаниях на растяжение:

1,2 - программа и характер изменения температуры, 3, 4 - соответственно программа и характер изменения нагрузки до разрушения образца

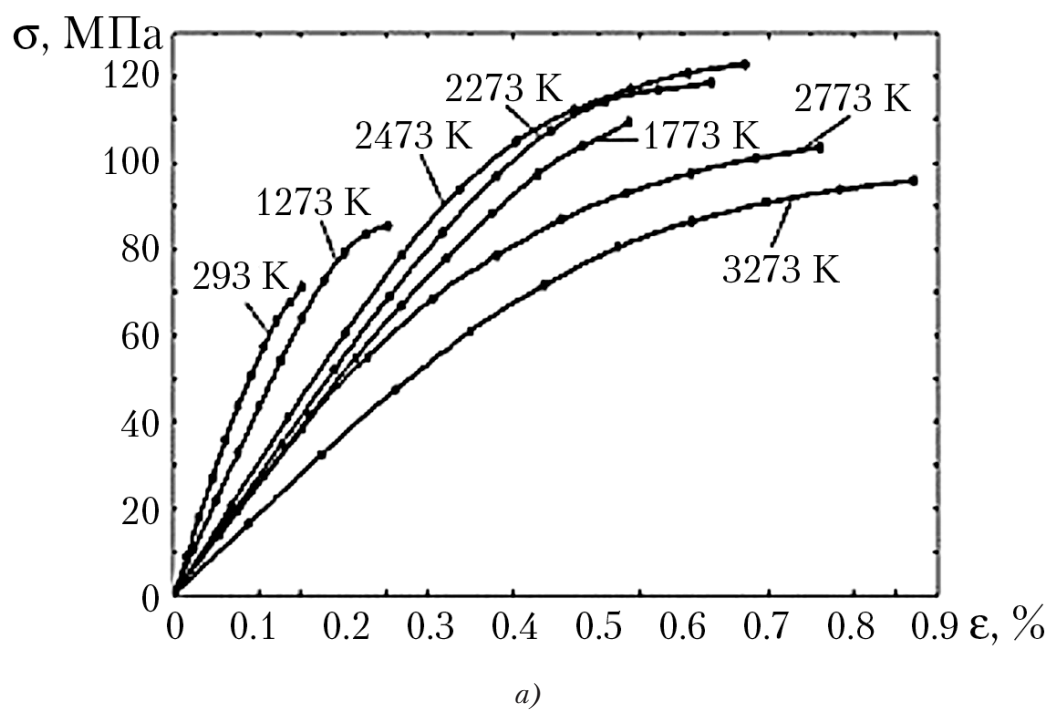

$\sigma, \mathrm{M \Pi \textrm {a }}$

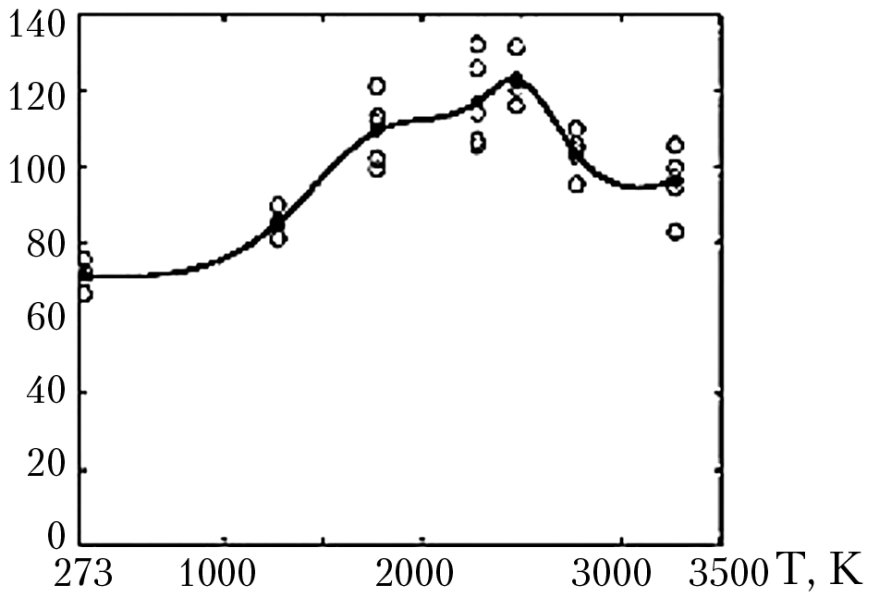

б)

Рис. 6. Влияние температуры на вид диаграммы деформирования “ $\sigma-\varepsilon$ ” $(a)$ и разрушающее напряжение (б) УУКМ при растяжении 


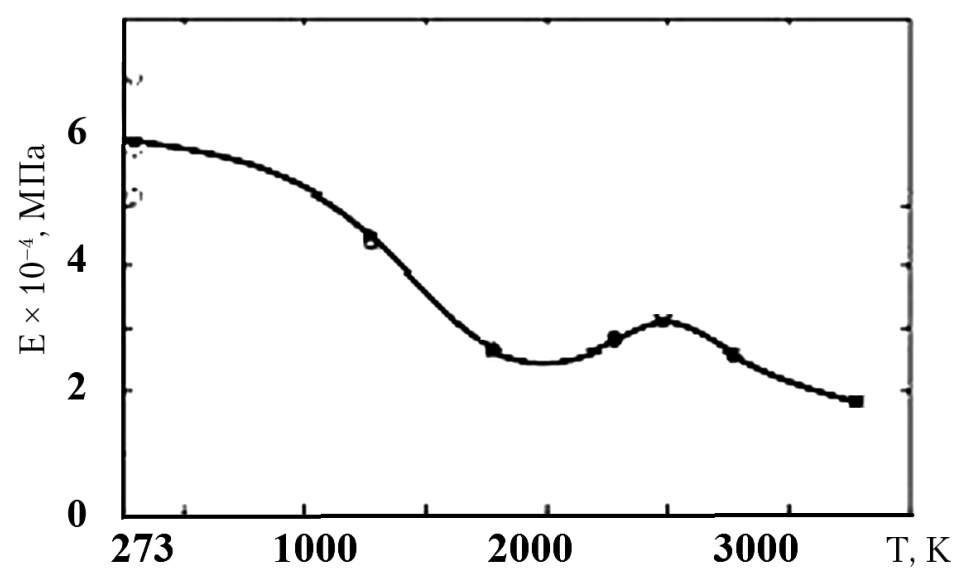

Рис. 7. Влияние температуры на модуль упругости УУКМ при растяжении

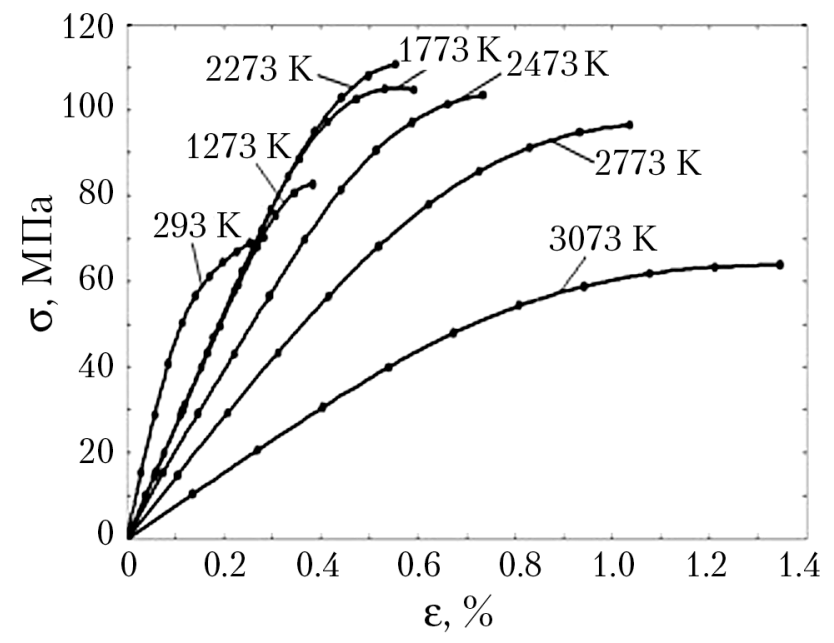

a)

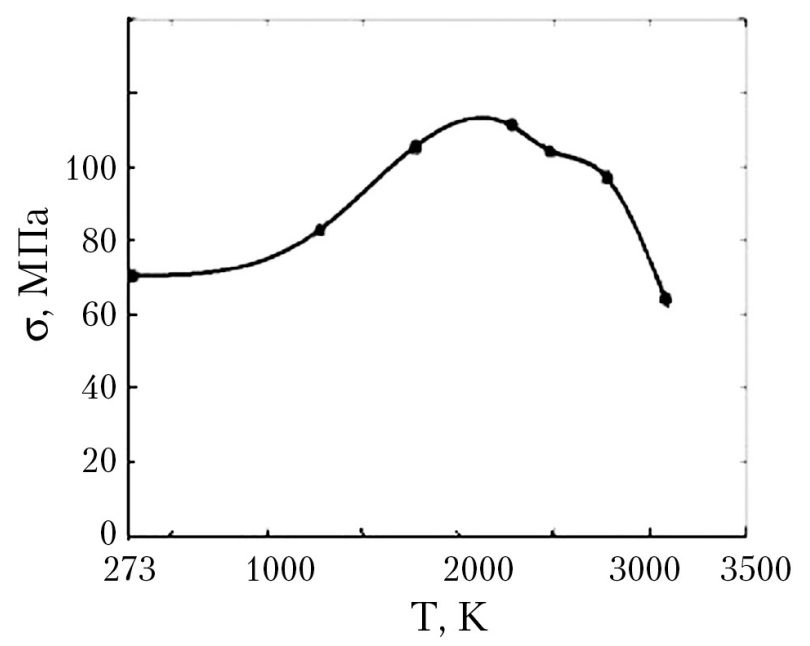

б)

Рис. 8. Влияние температуры на вид диаграммы деформирования “ $\sigma-\varepsilon$ ” (a) и прочность (б) УУКМ при сжатии

Такое существенное различие во влиянии температуры на прочность и деформативность материала связано со многими материаловедческими и технологическими факторами, обусловленными спецификой производства материала и изготовлением образцов из него. Очевидно, что каждый из факторов вносит свой вклад в накопление повреждений и определяет характер разрушение материала.

Представленные результаты исследований поведения УУКМ при различных видах механического нагружения и воздействии высоких температур свидетельствуют о необходимости учета особенностей их поведения в таких условиях при конструировании изделий из них. Они позволяют устанавливать границы рабочих температур, в которых УУКМ может быть применен.
Этим обусловливается необходимость разработки соответствующих методов и экспериментальных средств для получения достоверной информации, необходимой для конструирования изделий из УУКМ такого класса. Представленные выше экспериментальные и методические разработки в целом могут обеспечить выполнение указанных требований.

\section{Литература}

[1] Дзюба В.С., Кравчук Л.В., Куриат Р.И., Оксиюк С.В., Токарский В.А. Методика и результаты исследования прочности композитных материалов при кручении в условиях высоких температур (до 3300 К) //Механика композитных материалов, - 2011, №2, c. 335-342. 
Dzyuba V. S. ${ }^{1}$, Potapov A. M. ${ }^{2}$, Gusarova I. A. ${ }^{2}$, Kharchenko V. V. ${ }^{1}$, Kravchuk L. V. ${ }^{1}$, Drozdov A. V. ${ }^{1}$

${ }^{1}$ G. S. Pisarenko Institute for Problems of Strength of NAS of Ukraine. Ukraine, Kiev

${ }^{2}$ Yuzhnoye, State-owned Design Office named after M. K. Yangel. Ukraine, Dnepr

\section{STRENGTH OF CARBON-CARBON COMPOSITE MATERIALS (UUKM) AT HIGH TEMPERATURES (up to $3300 \mathrm{~K}$ )}

At present, composite materials (in aviation, rocket engineering, etc.) are widely used in technology because of their high strength, low specific gravity, their use in structures at high temperatures, where the metal does not work. A special place is occupied by carbon-carbon composites (CCCM) whose strength at high temperatures increases compared with the strength at room temperature. The purpose of this publication is to study the strength of the CCCM at temperatures of $300 \ldots 3300 \mathrm{~K}$ under tension and compression. At the present time in the literature there are data on these properties only up to $2200 \mathrm{~K}$, and CCCM are used in rocket engines at $T=3300 \mathrm{~K}$. To carry out these studies, a new technique has been developed, experimental tools have been created, and the results on the strength of the CCCM under tension, compression in the temperature range 300-3300 K have been obtained. [dx.doi.org/10.29010/084.5]

Keywords: composite material; strength; temperature.

\section{References}

[1] V. S. Dzyuba, L. V. Kravchuk, R. I. Kuriat, S. V. Oksiuk, V. A. Tokarskiy. Technique and results of the study of the strength of composite materials in torsion under high-temperature conditions (up to $3300 \mathrm{~K}$ ).// Mechanics of composite materials, 2011, №2, - P. 35-342. 